\title{
Factors affecting treatment adherence to atomoxetine in ADHD: a systematic review
}

\author{
This article was published in the following Dove Press journal: \\ Neuropsychiatric Disease and Treatment \\ 3 May 2016 \\ Number of times this article has been viewed
}

\section{Tamás Treuer ${ }^{1}$ \\ Luis Méndez ${ }^{2}$ \\ William Montgomery ${ }^{3}$ \\ Shenghu $\mathrm{Wu}^{4}$}

'Neuroscience Research, Eli Lilly and Company, Budapest, Hungary; ${ }^{2} \mathrm{Eli}$ Lilly de Mexico, Mexico City, Mexico; ${ }^{3}$ Global Patient Outcomes and Real World Evidence, Eli Lilly Australia Pty Ltd, West Ryde, NSW, Australia; ${ }^{4}$ Neuroscience Research, Eli Lilly Asia, Inc, Shanghai, People's Republic of China
Correspondence: Tamás Treuer Neuroscience Research, Eli Lilly and Company, $\mathrm{H}-1075$ Budapest, Madach I u I3-14, Hungary

Tel +36 I 3285 I 27

Fax +36 I 3285100

Email treuer_tamas@lilly.com
Abstract: The purpose of this paper was to systematically review the literature related to research about the factors affecting treatment adherence and discontinuation of atomoxetine in pediatric, adolescent, and adult patients with attention-deficit/hyperactivity disorder (ADHD). Medline was systematically searched using the following prespecified terms: "ADHD", "Adherence", "Compliance", "Discontinuation", and "Atomoxetine". We identified 31 articles that met all inclusion and exclusion criteria. The findings from this review indicate that persistence and adherence to atomoxetine treatment were generally high. Factors found to influence adherence and nonadherence to atomoxetine treatment in ADHD in this review include age, sex, the definition of response used, length of treatment, initial dose of treatment, comorbid conditions, and reimbursement. Tolerability was cited as an important reason for treatment discontinuation. More research is needed to understand those factors that can help to identify patients at risk for poor adherence and interventions that could improve treatment adherence early in the stage of this illness to secure a better long-term prognosis.

Keywords: atomoxetine, treatment discontinuation, adherence, compliance, ADHD medication, relapse

\section{Introduction}

Lack of information regarding the factors affecting adherence and discontinuation of effective pharmacotherapy for attention-deficit/hyperactivity disorder (ADHD) poses a significant challenge to the children and adolescents who are struggling with the disorder, their families, and the clinicians who treat the disorder. Although it still requires more research, it is speculated that long-term medication adherence is critical to achieving beneficial long-term treatment outcomes, especially with improved longer-term prognosis and reductions in disorder-specific difficulties. ${ }^{1-3}$ It is also important to understand the factors that influence treatment adherence, compliance, and discontinuation in these patients. Because most clinical drug trials require strict adherence to study medication regimen, they generally do not allow conclusions regarding medication adherence to be made in patients with ADHD treated in routine, naturalistic clinical settings. ${ }^{1-3}$

Rates of medication use have increased in recent years due to an increase in ADHD awareness, recognition, number of diagnosed patients, and treatment options; increased duration of use; as well as increased use among girls, preschool children, adolescents, and adults. ${ }^{4}$ Rates vary by geography, provider type, and patient characteristics, as well as by formulation of pharmacological agent.

In chronic mental disorders, such as ADHD, treatment nonadherence has an important short-term impact, affecting the initial efficacy and tolerability of treatment, 
and a longer-term impact, associated with poorer medical outcomes and a higher economic burden of disease. . $^{5,6}$ Nonadherence was associated with poorer response and less improvement in clinical severity. ${ }^{7}$ For children, adolescents, and adults with ADHD, treatment adherence has been shown to be especially poor, regardless of the treatment options chosen, ie, stimulant or nonstimulant, pharmacologic or nonpharmacologic. Reported levels of nonadherence in children and adults range between $15 \%$ and $87 \%{ }^{8}$ It could also be hypothesized that the sooner ADHD is treated effectively by clinicians, the more likely patients have a favorable long-term outcome and prognosis. ${ }^{9}$ This could be especially important in chronic conditions, such as ADHD, that develop in patients at a younger age. ${ }^{9}$ Effective treatment can work only if patients adhere to it, and physicians usually assume that patients and caregivers may usually adhere to treatment if they find it effective.

Nonadherence to ADHD medications has been noted as a barrier to positive treatment outcomes, such as improvements in intellectual or cognitive functionality and academic achievement and reductions in social difficulties, family dysfunction, unintentional injury, and risk of future substance abuse, ${ }^{10}$ and has been associated with poorer response and less improvement in clinical severity. ${ }^{7}$ As treatment adherence should be regarded as a shared agreement between the patient or patient's family and the clinician, these data might reflect an underlying poor alliance in the decision-making process that needs to be explored. Nonadherence may also result, in part, from a lack of understanding of the importance of medication adherence during the treatment initiation and maintenance phases of treatment in achieving and maintaining the desired outcomes. In addition, the World Health Organization defines treatment adherence as the extent to which a person's behavior - for example, taking medication, following a diet, and/ or executing lifestyle changes - corresponds with agreed recommendations from a health care provider. ${ }^{11}$ Nonadherence can take many forms. It may be a patient taking a lower dose than prescribed or making any other change to the doctor's recommendations and not just stopping the treatment. In short, adherence to pharmacologic treatment means following exactly what the doctor recommended with respect to the dose to be taken and the frequency and duration of treatment. ${ }^{12}$

The following definition for medication adherence as described by Cramer et $\mathrm{al}^{13}$ was used in this review. Medication adherence (synonym: compliance) was defined as "the degree or extent of conformity to the recommendations about day-to-day treatment by the provider with respect to the timing, dosage, and frequency" and "the extent to which a patient acts in accordance with the prescribed interval, and dose of a dosing regimen". ${ }^{13}$ Persistence was not included as a search term as it refers to the continuation of a treatment for the prescribed duration, ${ }^{13}$ whereas the intent of the review was to focus on treatment adherence in general terms. However, articles that were included in this review that also discussed persistence were indicated.

There is an increasing recognition that "treatment engagement" may have a positive influence on treatment adherence/compliance and continuation and lead to better outcomes. ${ }^{14}$ Whereas compliance refers to how well an individual obeys the directives of health care providers, engagement refers to the involvement of the patient in decision making and coordinating their own needs with professional advice and available information. ${ }^{15}$ As the concept of engagement is relatively novel and not often reported as an outcome measure in clinical studies, ${ }^{16}$ this factor was not included in the present search. The Center for Advancing Health has compiled a list of measurable actions to aid in assigning treatment engagement. ${ }^{15}$

Atomoxetine is a selective norepinephrine reuptake inhibitor and is a nonstimulant that has been approved for the treatment of ADHD symptoms in pediatric, adolescent, and adult patients in several countries. ${ }^{17-19}$ It has favorable adverse effect and safety profiles and no demonstrable abuse liabilities and has been cited as having a better than expected maintenance of response against ADHD symptoms. ${ }^{20}$ Consequently, atomoxetine is beneficial in short- and longterm treatment options for ADHD. ${ }^{17}$

In this paper, the authors reviewed the available literature with the following objectives: 1) to determine the levels of medication adherence/compliance and of discontinuation in atomoxetine-treated patients described in the literature; 2) to explore factors affecting treatment adherence and nonadherence in ADHD; 3 ) to examine the potential relationship between treatment adherence/nonadherence and long-term outcomes, functionality, and cost-effectiveness; and 4) to investigate potential links regarding the differences in remission with atomoxetine in long-term treatment vs discontinuation, in maintenance of response.

\section{Materials and methods \\ Database search strategy}

This review follows guidelines proposed by the Preferred Reporting Items for Systematic Reviews and Meta-Analyses (PRISMA) group. ${ }^{21}$ No review protocol was registered for 
this study. To find eligible studies, abstracts were screened and selected from an accepted scientific database based on the following inclusion and exclusion criteria.

\section{Inclusion criteria}

Criteria for inclusion in this systematic review were the following: 1) full-text primary publications of real-world studies; 2) ADHD treatment guidelines for the USA, Canada, the UK, Germany, France, Spain, Italy, Sweden, and the Netherlands, as well as any general European guidelines; 3) observational studies based on real-world data; 4) Phase IV clinical trials, in which at least $80 \%$ of study population (children, adolescents, or adults) have ADHD as the primary disorder; 5) utilized atomoxetine as a drug treatment; 6) reported discontinuation/switching results or reported reasons for discontinuation/switching and/or adherence/compliance of ADHD drug treatment; 7) published in English; and 8) published from January 2003 through February 2015.

\section{Exclusion criteria}

Exclusion criteria consisted of the following: 1) nonprimary publications of real-world studies; 2) conference abstracts or posters, congress proceedings, books, chapters, addresses, bibliographies, biographies/lectures, case reports, author commentaries, or letters; 3) reviews/meta-analyses; 4) preclinical studies; 5) Phase I-III clinical trials; 6) prognostic studies; 7) genetic studies; 8) nonhuman subjects; 9) patients without ADHD; 10) $80 \%$ of study population without ADHD as the primary disorder; 11) no drug treatment; 12) drug treatment not listed in the inclusion criteria; 13) did not report discontinuation/continuation results or compliance or adherence rates specific to atomoxetine treatment, 14) publication was not in English; and 15) published before January 2003 and after February 2015.

Literature was retrieved after searching MEDLINE on February 20, 2015, with the following search terms: ADHD AND Adherence AND Atomoxetine; ADHD AND Compliance AND Atomoxetine; and ADHD AND Discontinuation AND Atomoxetine. All retrieved abstracts were initially screened, and studies that clearly met the exclusion criteria were excluded. The remaining studies were rescreened, and only articles meeting the aforementioned inclusion/exclusion criteria were included. The search terms and the inclusion/exclusion criteria were established by all the authors, all of who reviewed and agreed upon the final terms. The data extraction was performed by an external consultant enlisted for this purpose.

\section{Results Literature search results}

A total of 114 unique potentially relevant articles were retrieved with the search strategies described earlier. Of those, 31 articles were included in the current review. Table 1 displays a summary of studies included in this review. A total of 83 retrieved references were excluded because the reference was a review or meta-analysis ( $\mathrm{n}=29)$, was not in English $(\mathrm{n}=5)$, was a case report $(n=3)$, was an author commentary $(n=2)$, was published before January $2003(\mathrm{n}=1)$, did not contain discontinuation/continuation results or compliance/adherence rates specific to atomoxetine $(\mathrm{n}=12)$, included study results of patient population $\leq 10(\mathrm{n}=1)$, and was duplicated (required manual removal, $\mathrm{n}=30$ ) (Figure 1).

\section{Medication treatment adherence/ compliance}

The topic of treatment adherence or compliance in pediatric, adolescent, and adult patients with ADHD was specifically addressed by 13 of the 31 articles included in the present review (Table 1). There was considerable variation in the way treatment adherence (or compliance) was defined and quantified, and considerable variation in the manner the studies were conducted. In a 1-year study of children and adolescents with ADHD, treatment adherence was determined with the Pediatric Compliance Self-Rating (PCSR) instrument and items 1-4 of the Medication Adherence Rating Scale (MARS) and gave an adherence rate for atomoxetine was $67.5 \%$ at 1 year, and it declined over time. ${ }^{22}$ In a post hoc analysis of data obtained from the Strattera Support Service, treatment adherence was defined as the proportion of patients who reported taking atomoxetine at week 12 , regardless of any previous interruptions in treatment. ${ }^{23}$ That study reported an adherence of $90.5 \%$ for atomoxetine. ${ }^{23}$ In Norway, a follow-up questionnaire was sent to adult patients with ADHD receiving pharmacologic treatment for a mean of 4.5 years. ${ }^{24}$ Treatment adherence, defined by patients self-reporting not missing a single dose within the past week, was 50\% for atomoxetine. ${ }^{24}$ In a randomized, clinical trial (RCT), treatment adherence was determined by direct questioning and a review of returned medications. ${ }^{25}$ Only three of the 49 patients randomized to atomoxetine were found noncompliant at week $10 .{ }^{25}$

Most of the remaining studies addressing treatment adherence were performed by a post hoc review of prescription claims, the primary care database (UK), or treatment and hospitalization records. ${ }^{6,26-31,32}$ In those studies, treatment adherence was estimated by determining the proportion of days covered by medication divided by the total number of 


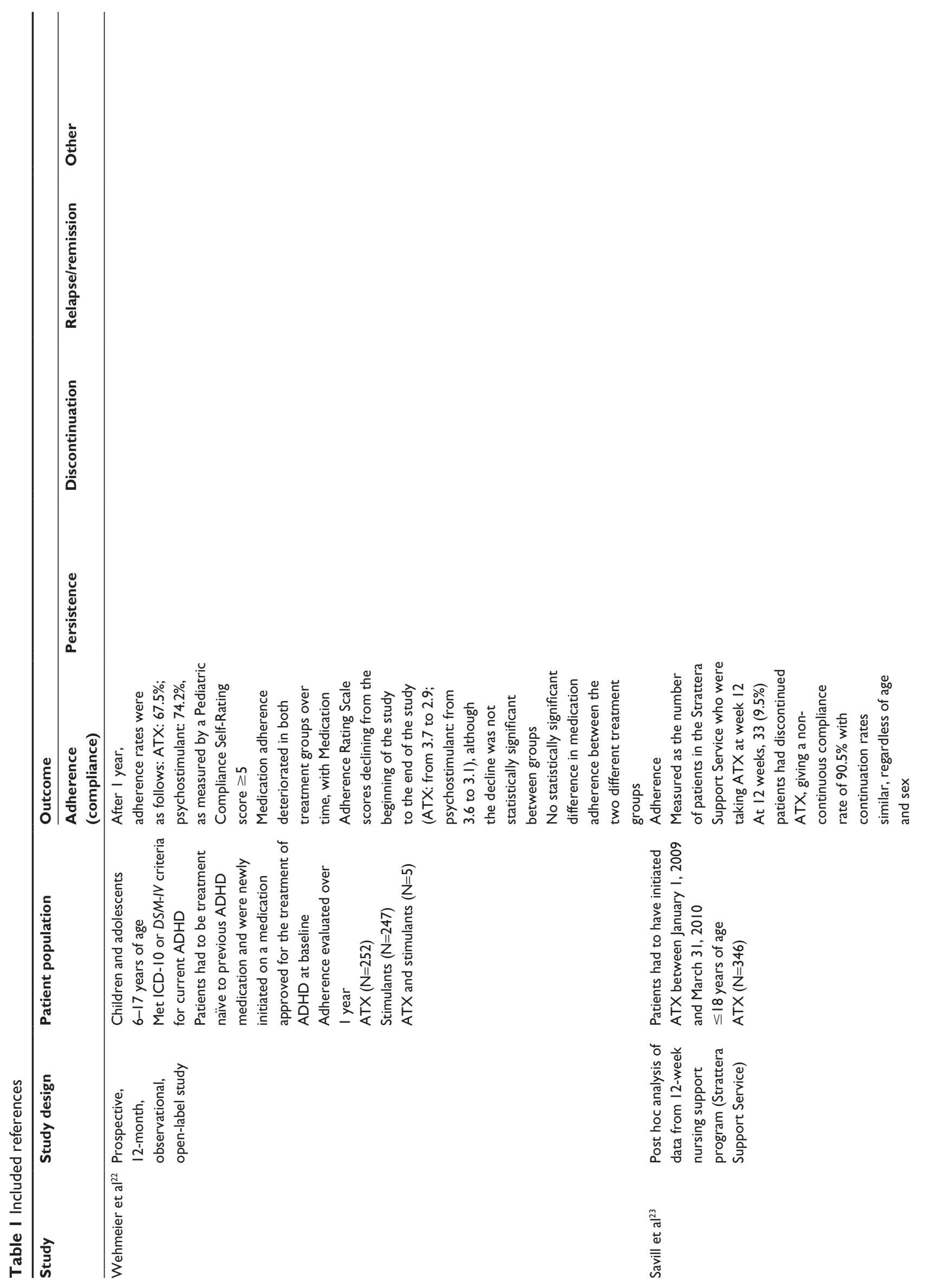



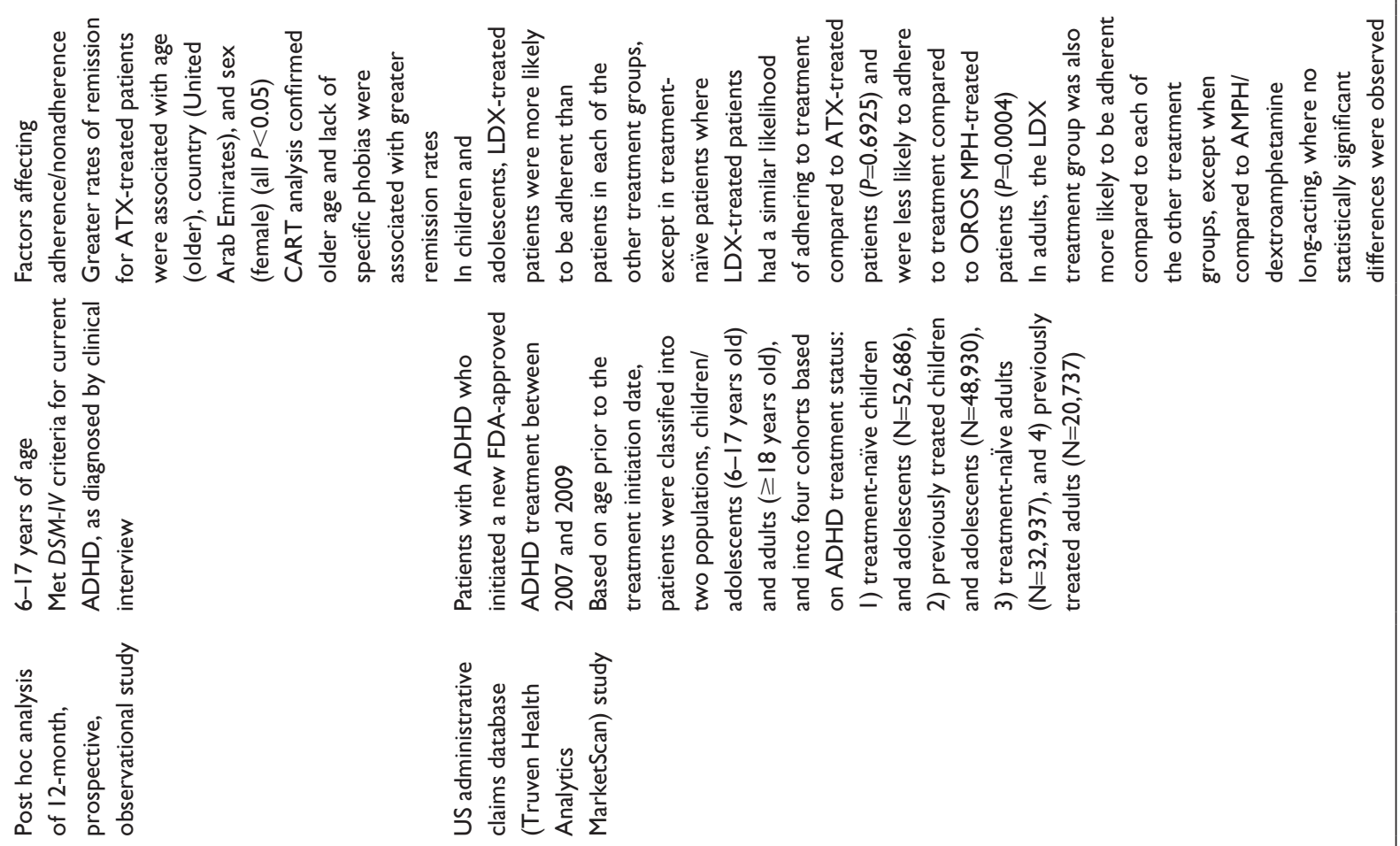

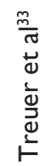

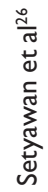




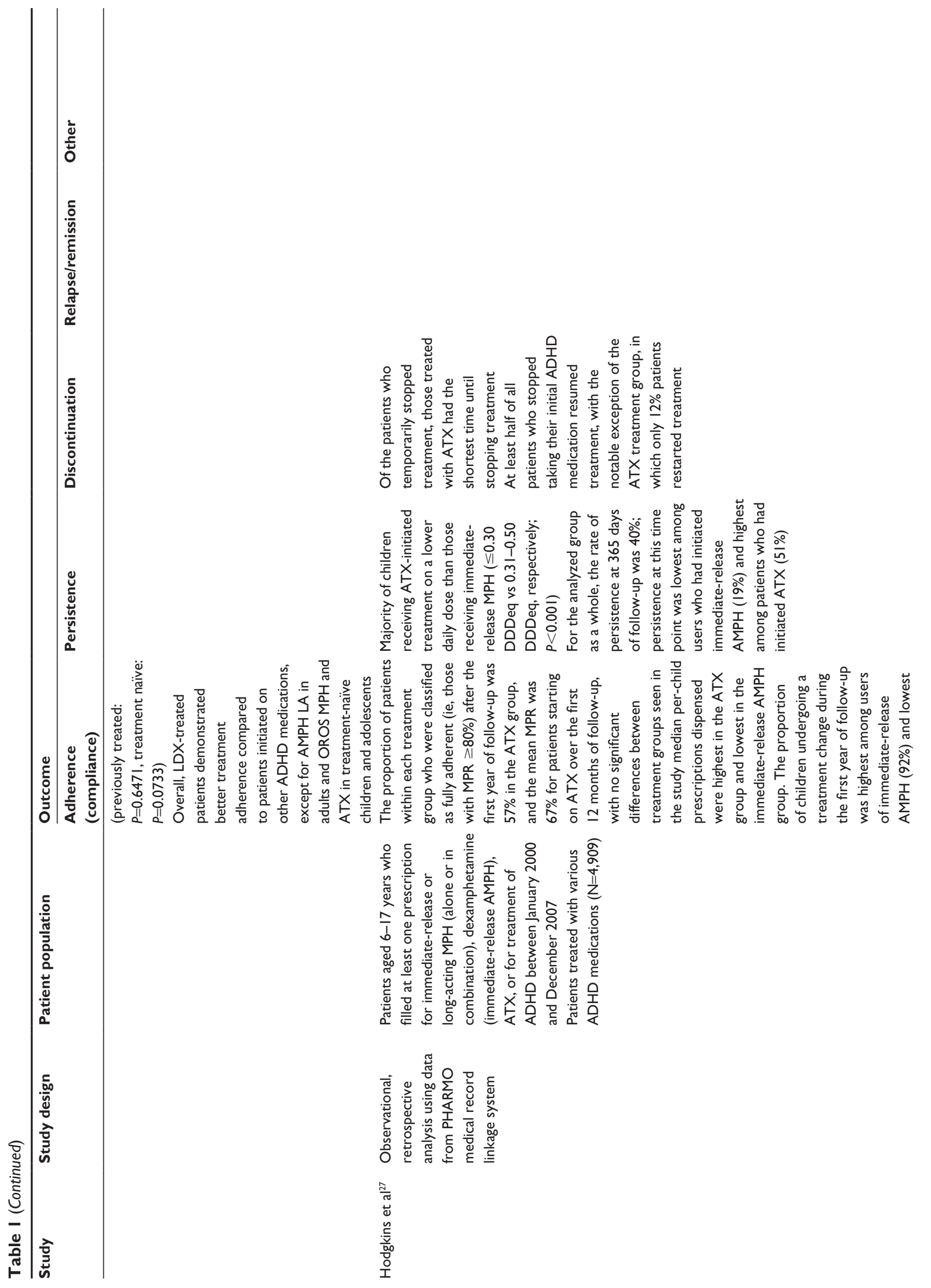



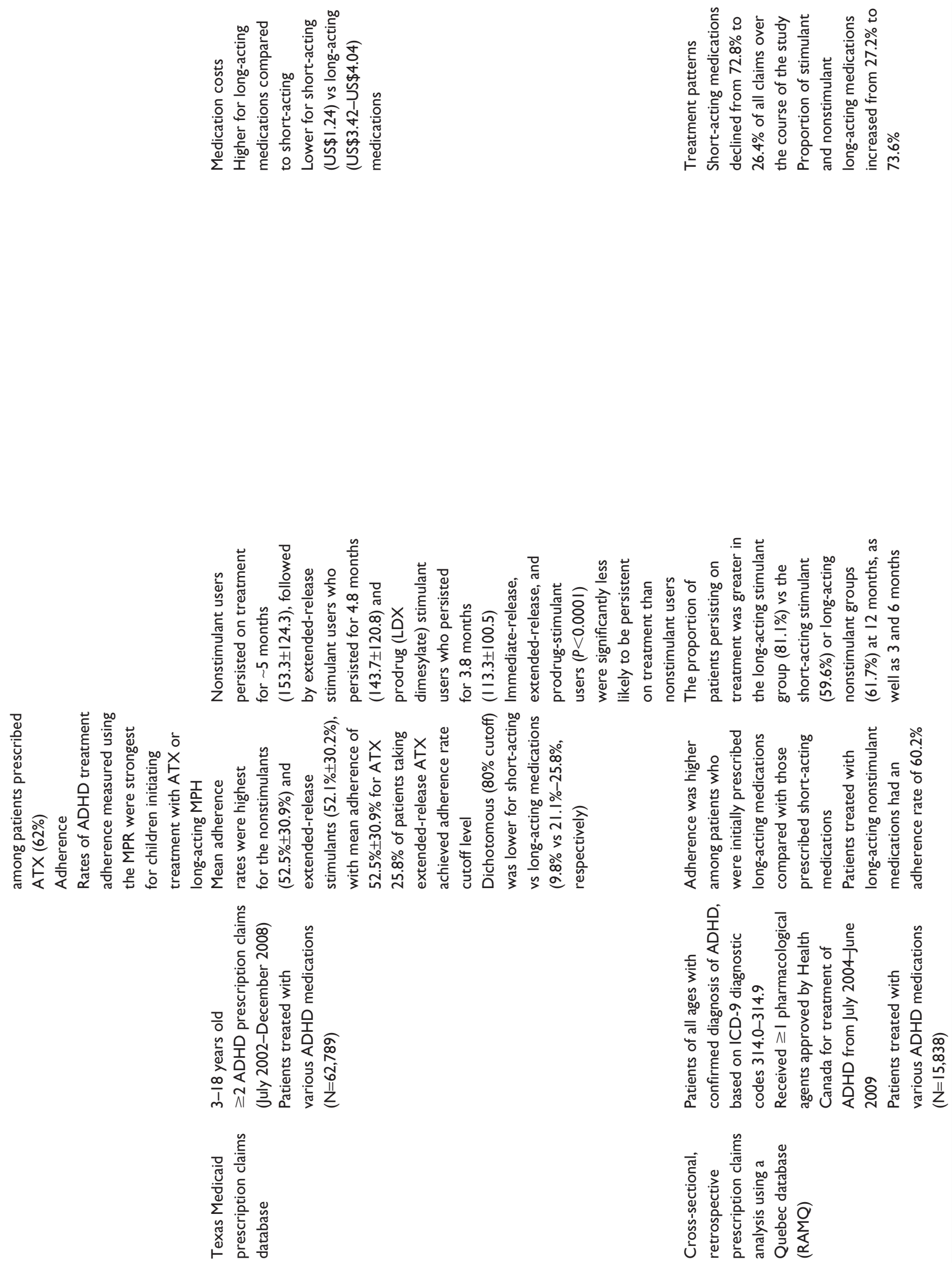

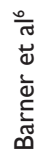

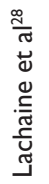




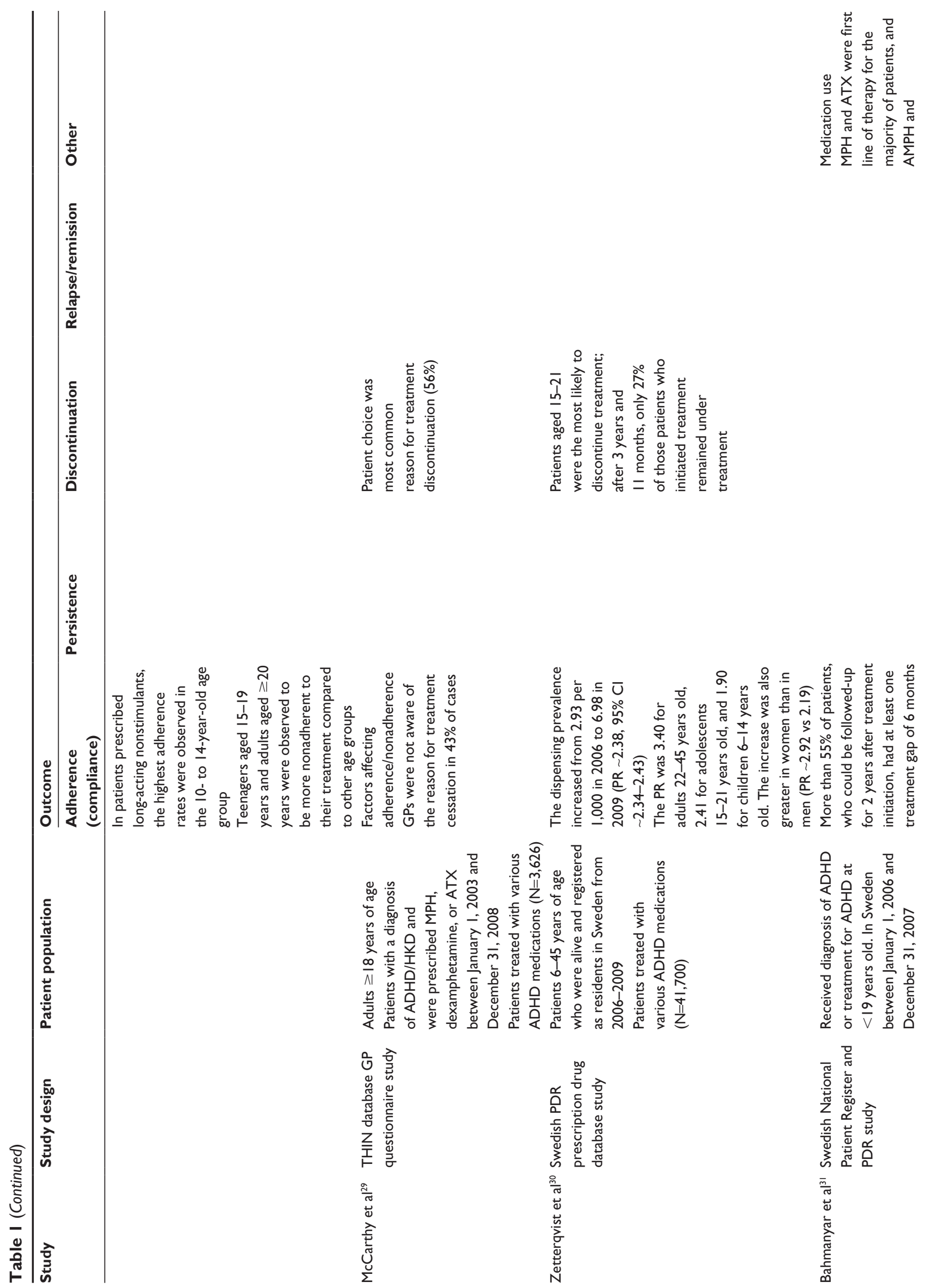



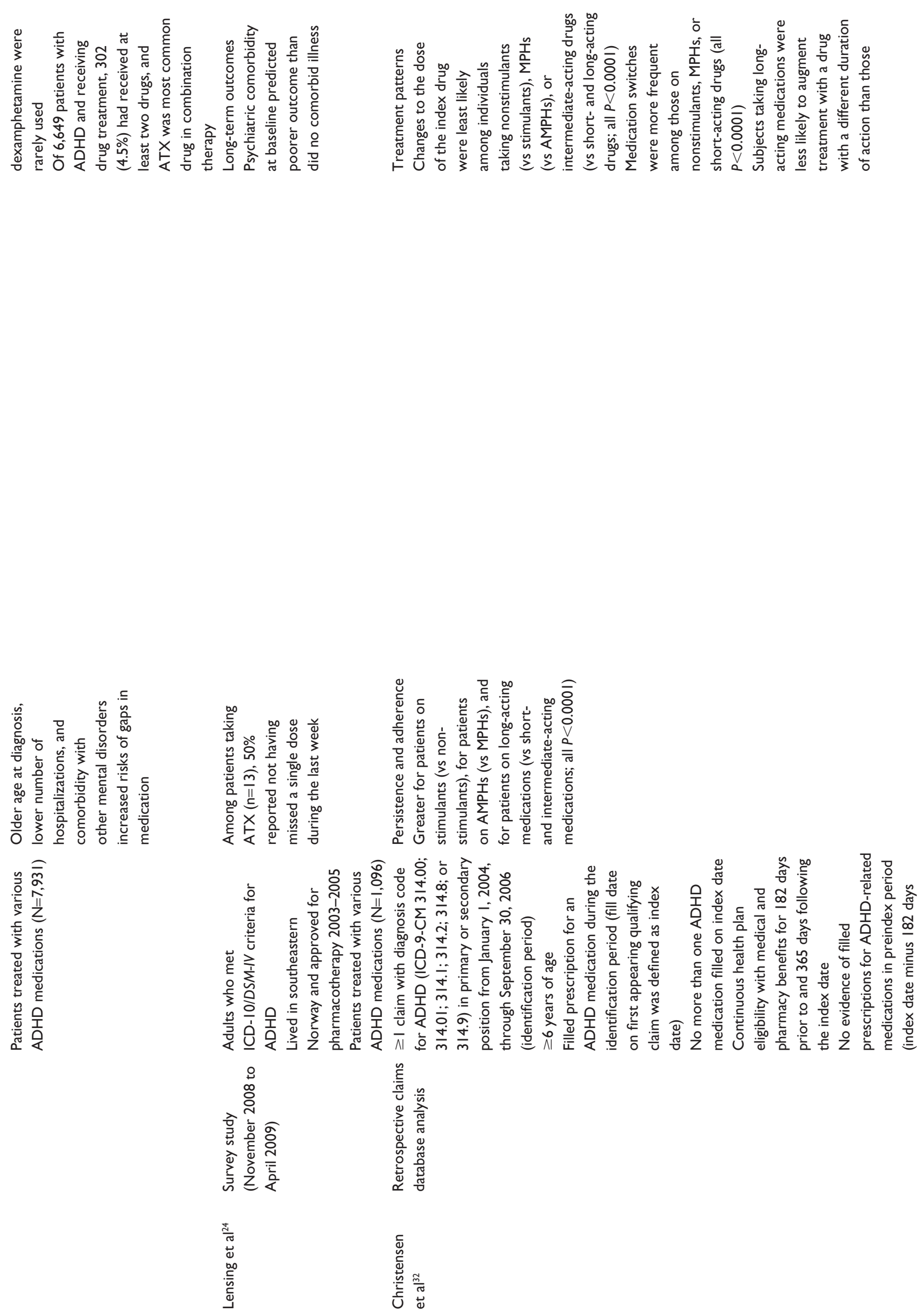


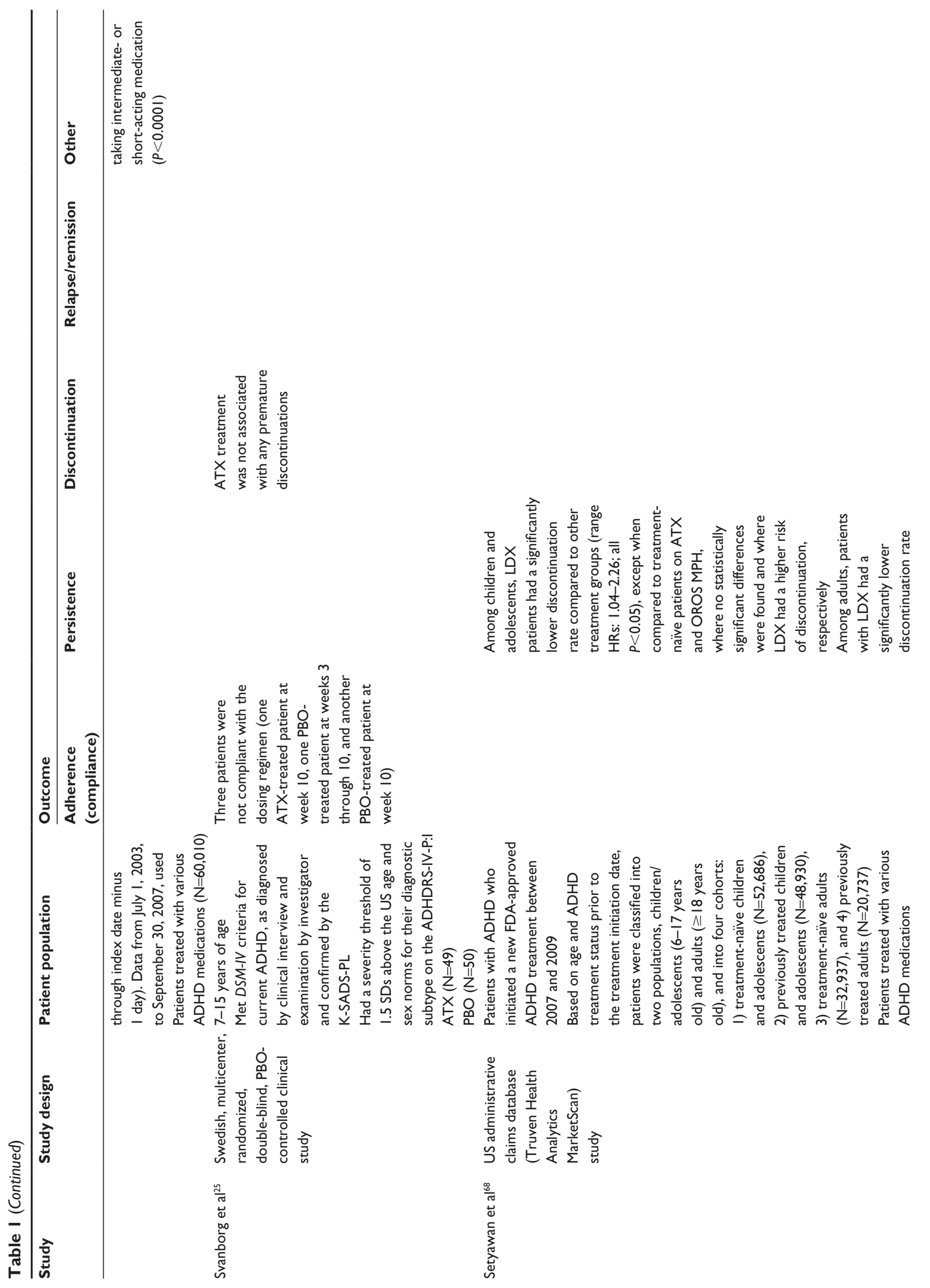



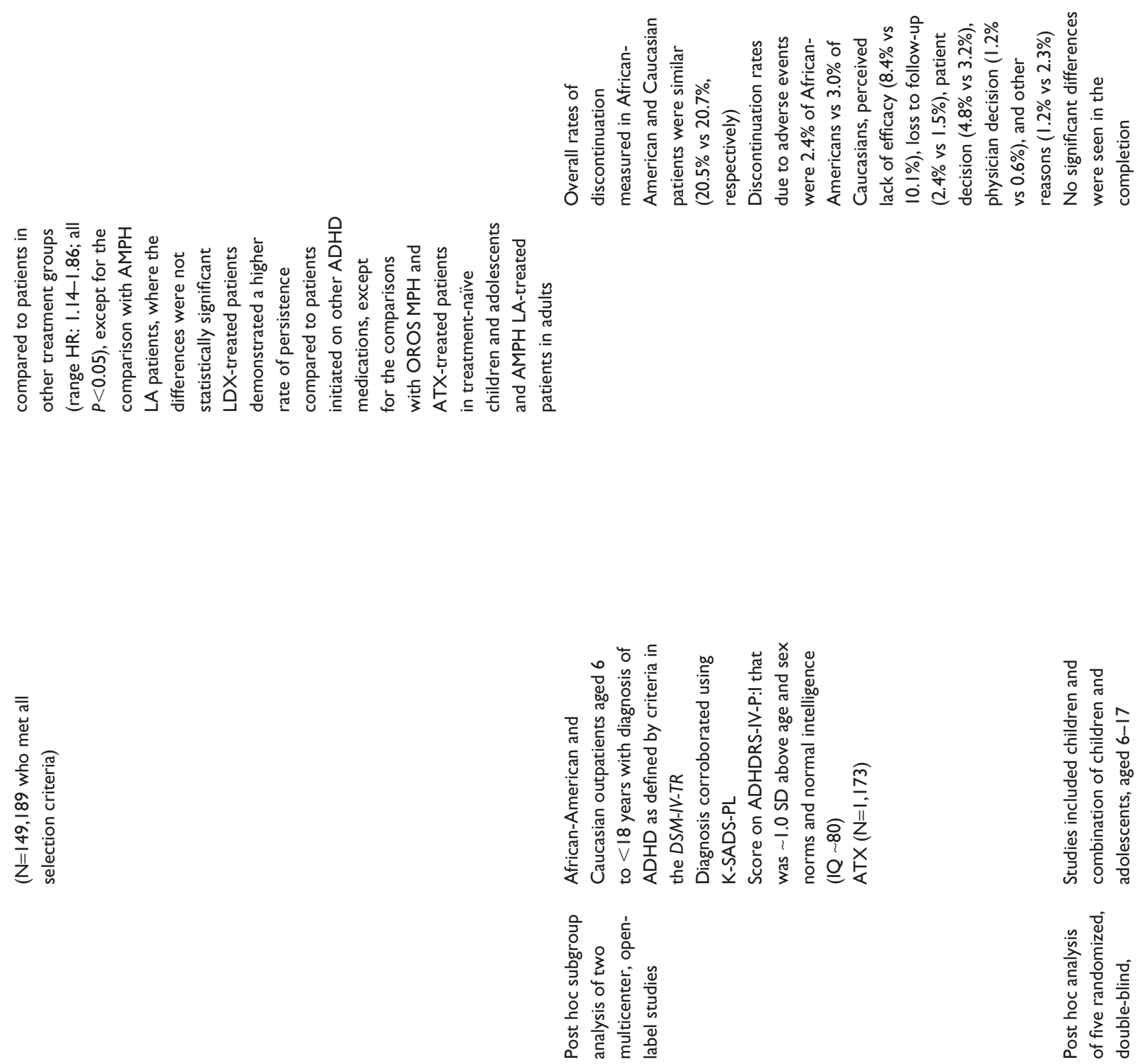

$\frac{0}{\sqrt{0}}$
$\frac{4}{0}$
$\overline{\overline{0}}$
$\frac{0}{\overline{0}}$

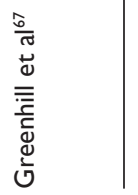




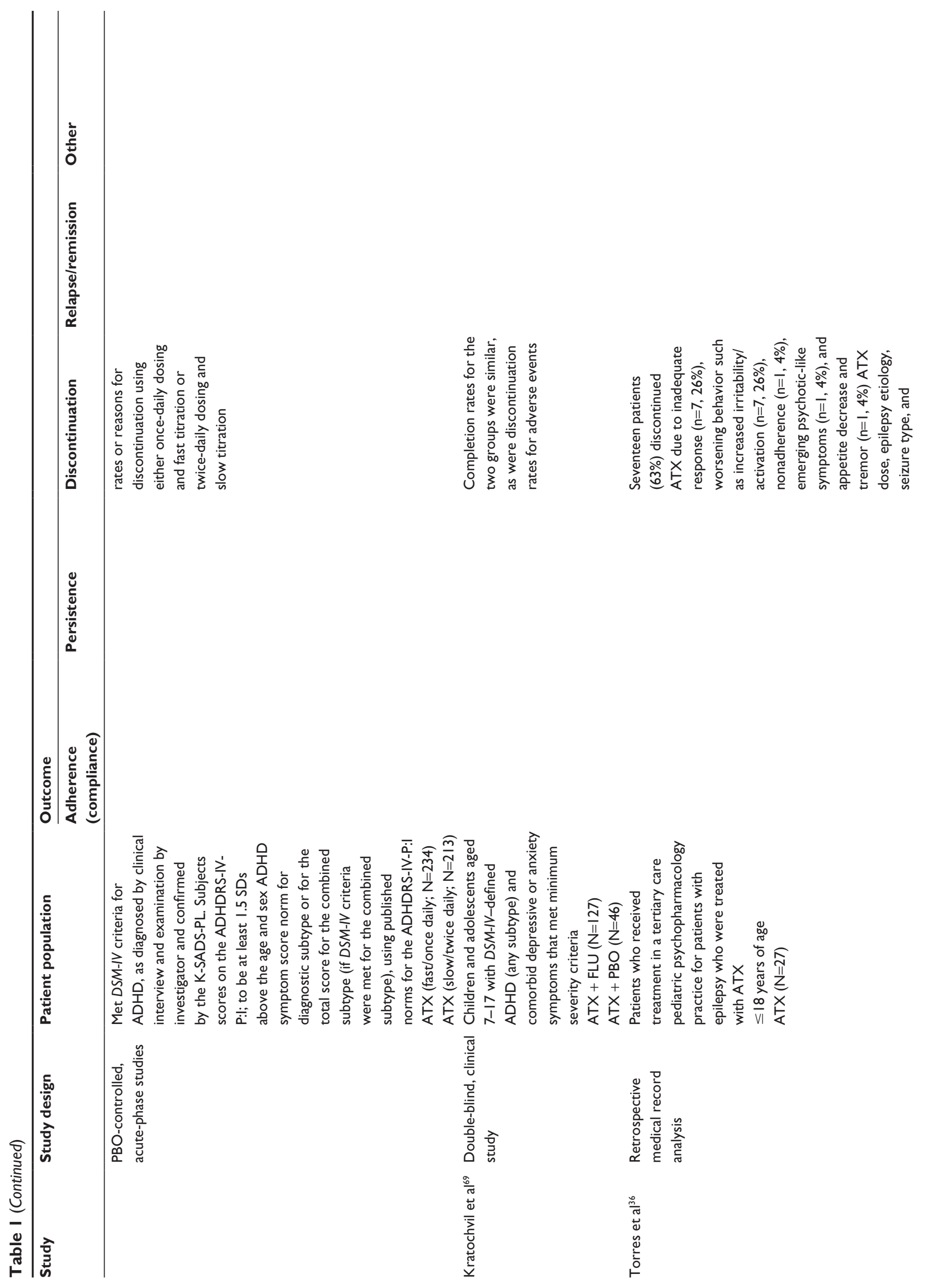



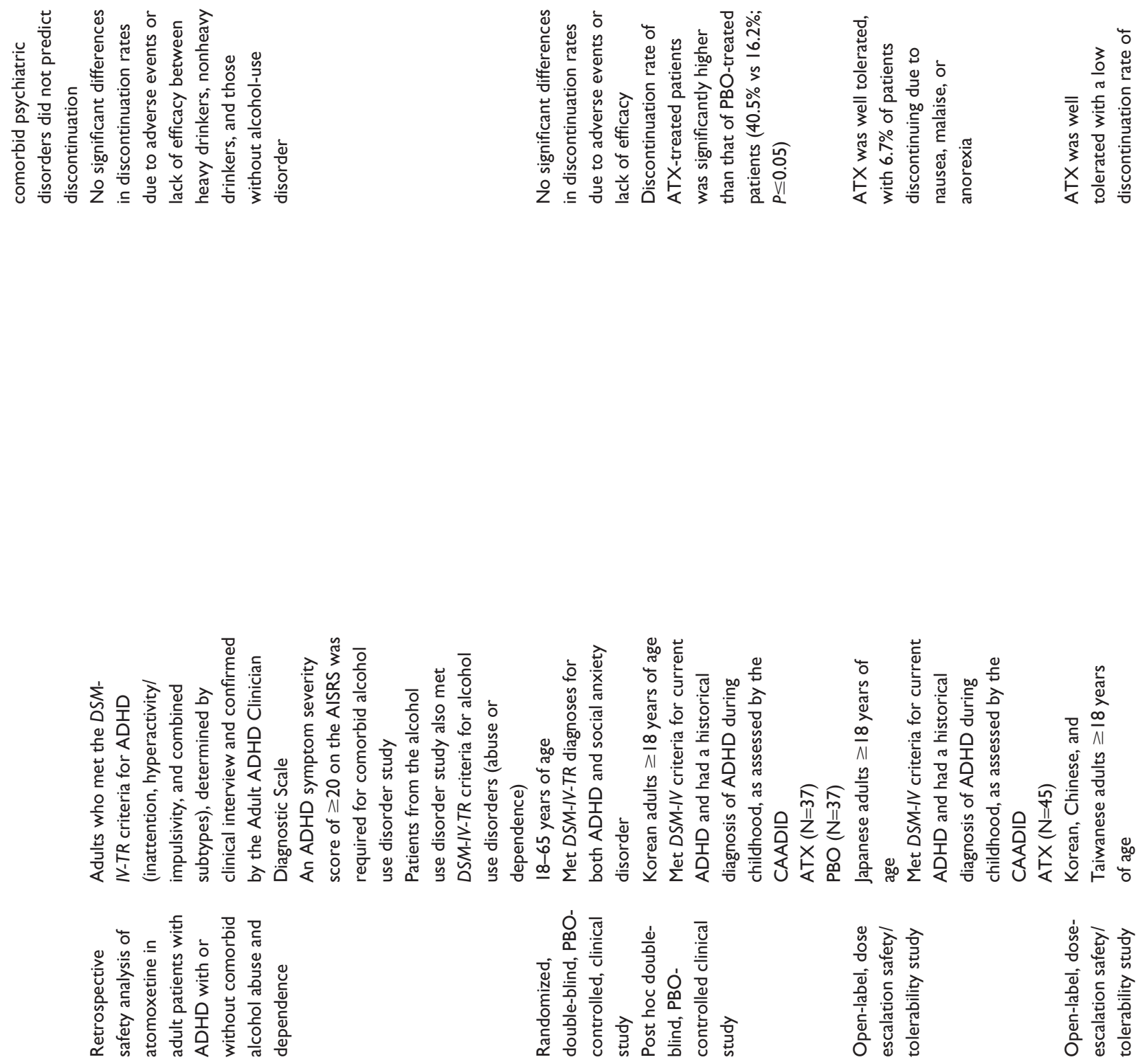

$\frac{\frac{\pi}{\frac{\pi}{0}}}{\frac{1}{4}}$

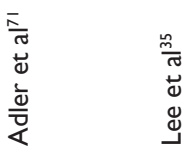

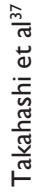

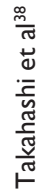




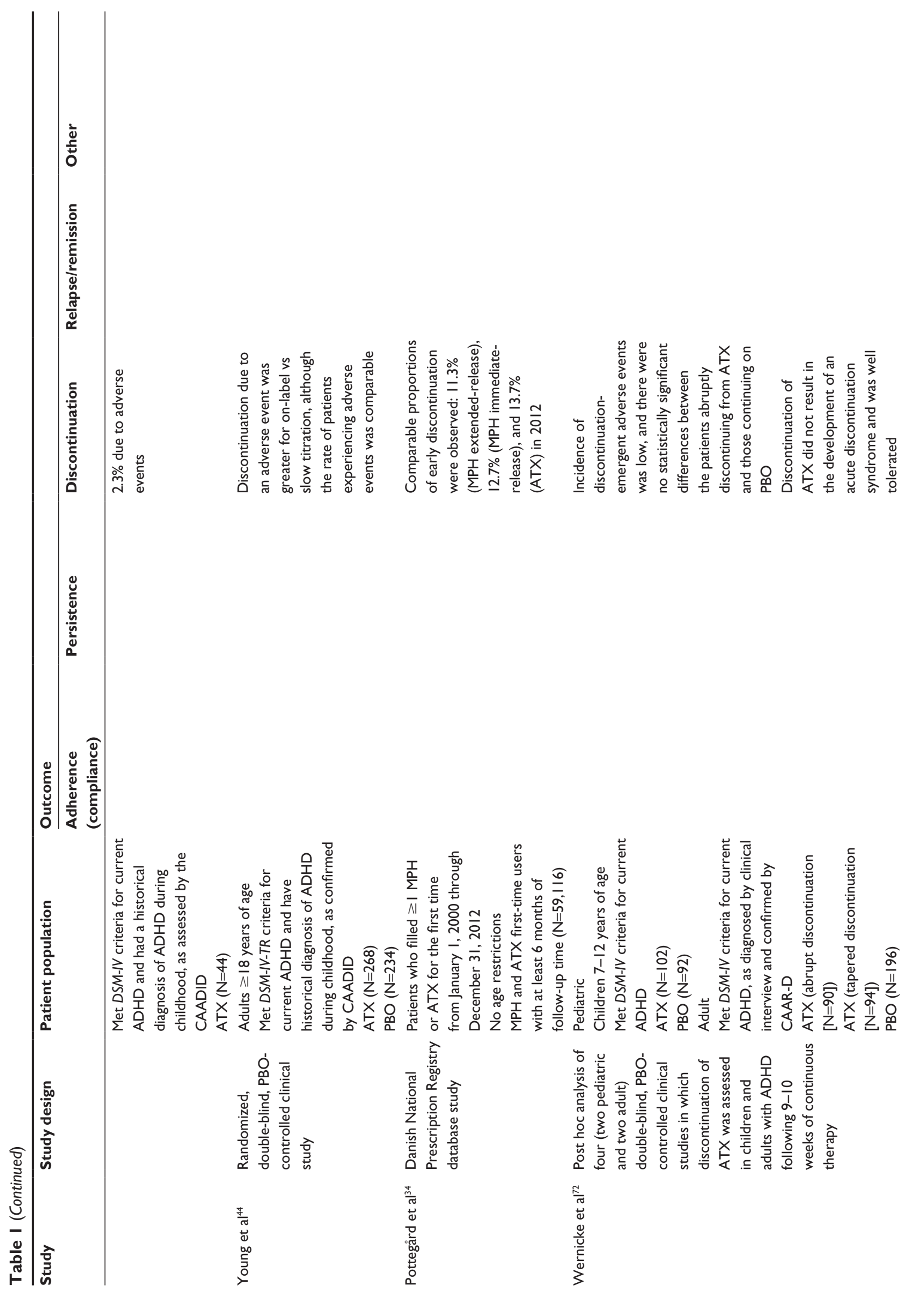



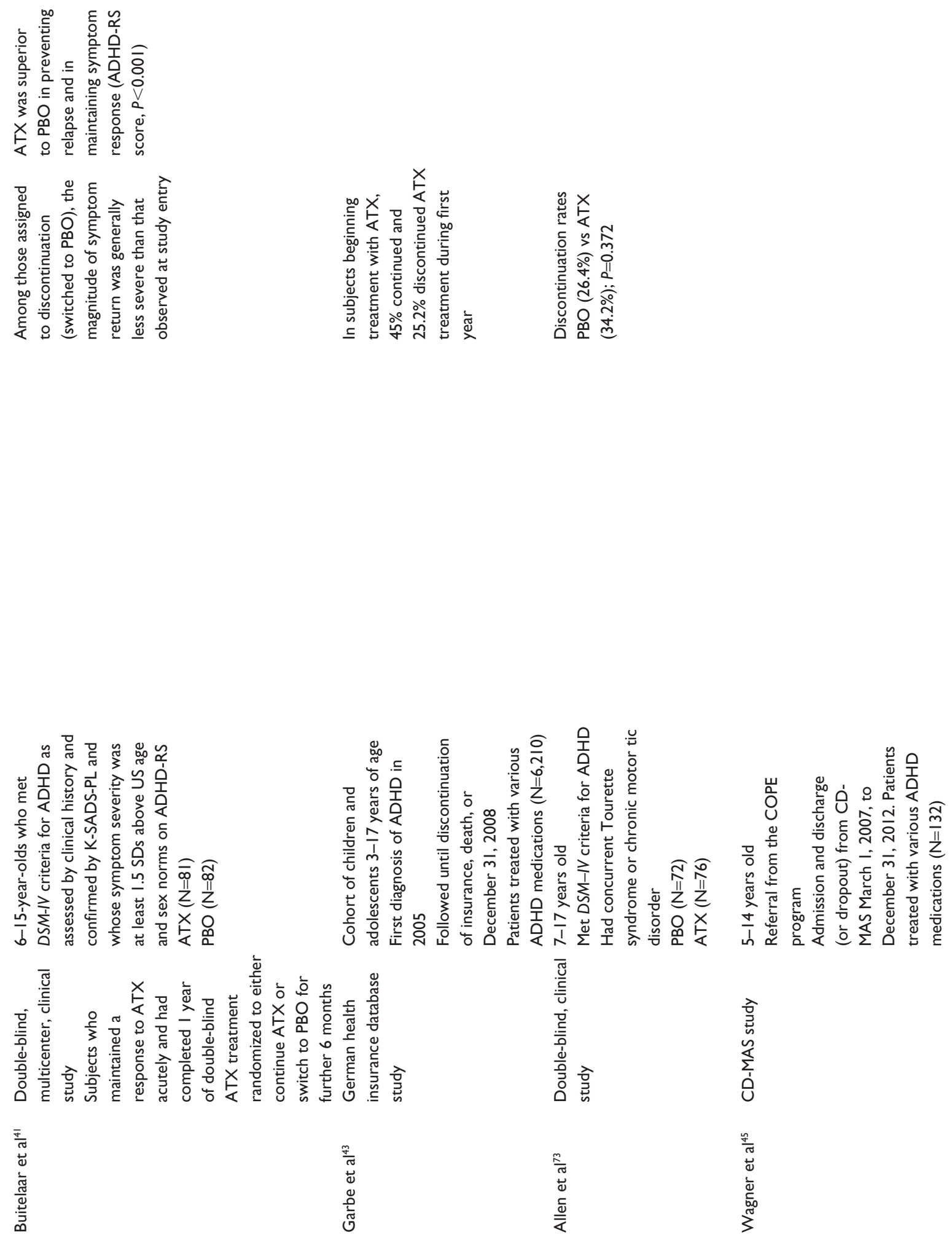

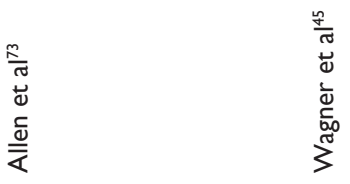




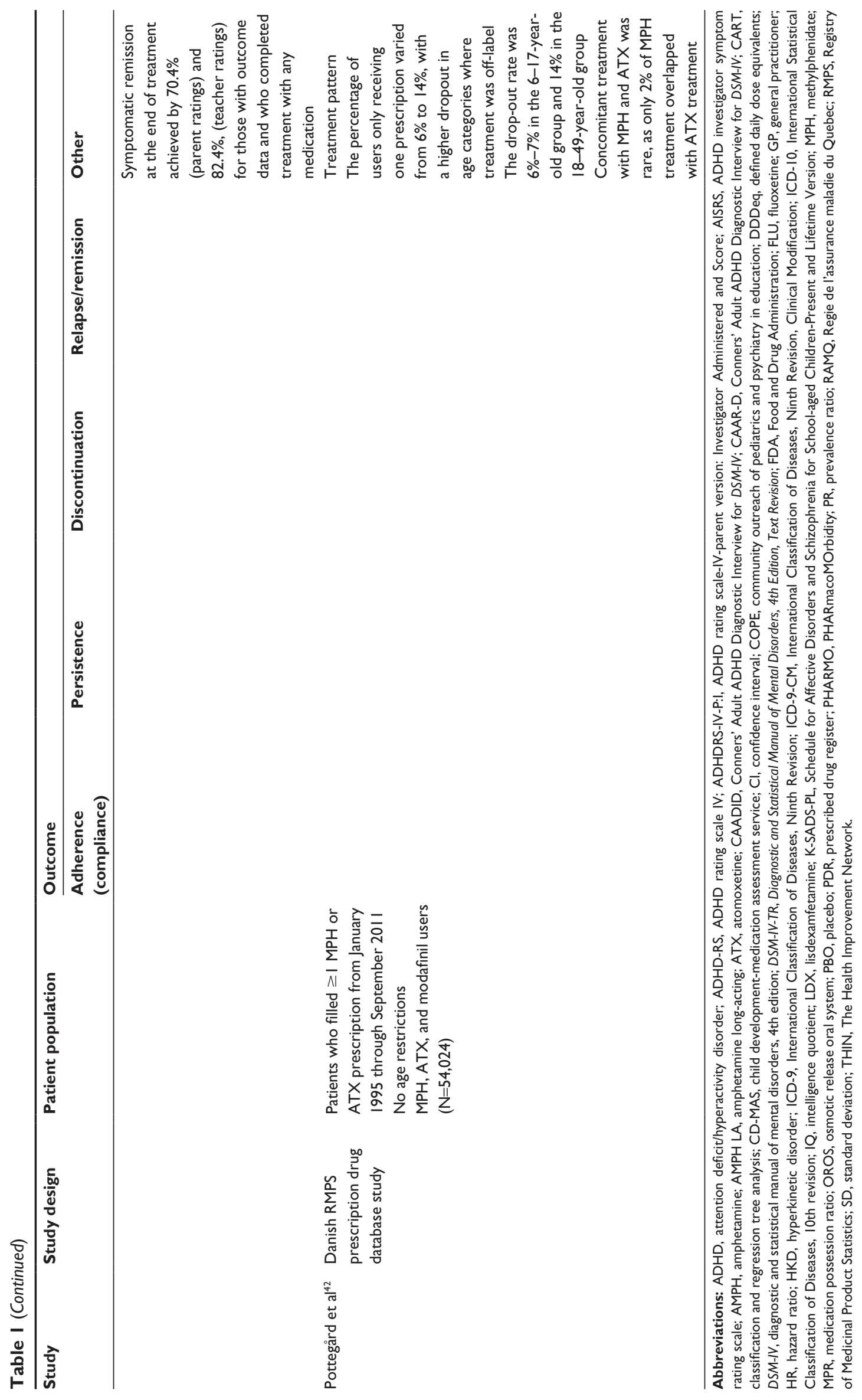




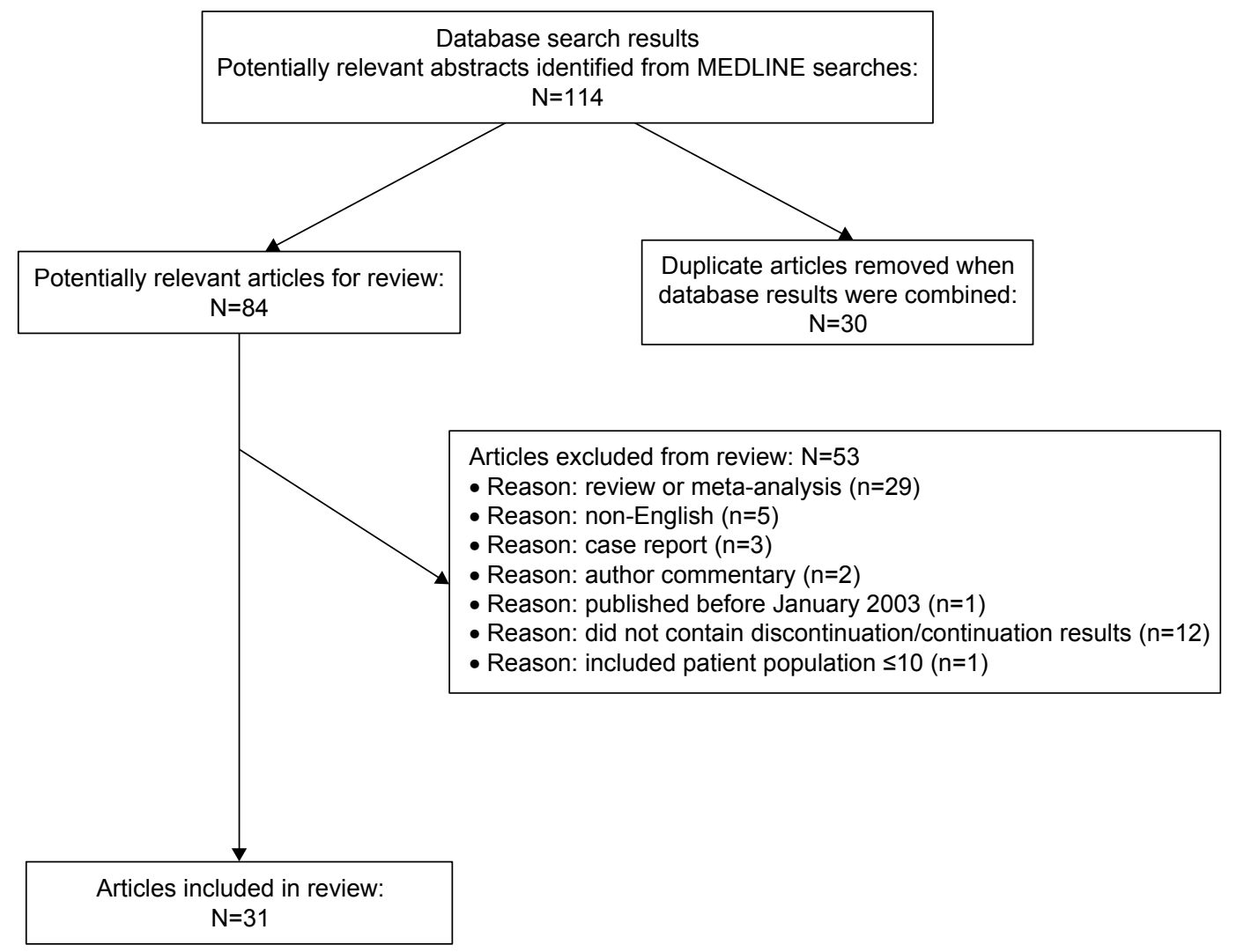

Figure I PRISMA diagram of the literature selection criteria.

Abbreviation: PRISMA, preferred reporting items for systematic reviews and meta-analyses.

days in the study period. In those studies, treatment adherence was indicated by a ratio of $\geq 80 \%{ }^{6,26-30,32}$ or by a 6-month gap in treatment. ${ }^{31}$ In a post hoc analyses of a 12 -month prospective study of atomoxetine, the degree of treatment adherence was not determined, but the factors associated with treatment adherence were examined. ${ }^{33}$ Adherence to a treatment plan for chronic conditions, which includes ADHD, and where multiple doses are required, tends to be poor. ${ }^{33}$ Consistent with these points, patients taking long-acting drugs tend to show better treatment adherence than those taking shorteracting formulations, ${ }^{28}$ and adherence to an atomoxetine regimen deteriorates over time. ${ }^{22,27}$ For example, the adherence rates for atomoxetine ranged from $64 \%$ at 3 months to $44 \%$ at 1 year. ${ }^{27} \mathrm{~A}$ factor that may influence treatment adherence rates reported in school-age children is a tendency of some parents to provide medication only on school days, resulting in treatment gaps corresponding to weekends, holidays, and summer vacation. ${ }^{6,31}$ Females show significantly better treatment adherence than males. ${ }^{6}$

\section{Medication persistence}

Persistence is defined as the period of time during which a patient continues taking a treatment. ${ }^{13}$ It differs from adherence in that adherence refers to how well a patient conforms to the entire treatment requirements in terms of dose, frequency, and timing within a prescribed period of time. ${ }^{13}$ Pediatric patients taking atomoxetine persisted for 5 months in one study ${ }^{6}$ and showed a $51 \%$ rate of persistence over 1 year and were more likely to persist than patients taking stimulants. ${ }^{27}$ When adult and pediatric patients were considered, the persistence rate at 1 year was similar between atomoxetine (62\%) and short-acting stimulants $(60 \%)$ and less than long-acting stimulants $(81 \%) .{ }^{28} \mathrm{~A}$ retrospective claims analysis of pediatric and adult patients reported a significantly $(P<0.0001)$ greater persistence for patients on stimulants when compared to nonstimulants. ${ }^{32}$ Overall, persistence is low among nonstimulant and stimulant ADHD treatments in children and adults and tends to be lower in treatment-naïve patients. ${ }^{26}$

\section{Medication discontinuation}

Of the articles included in the present review, 18 included a discussion of drug discontinuance. It differs from persistence in that this includes patients who discontinue outside of a prescribed period within a study and includes patients who would resume the treatment after a period of time. Overall, 
the rate of discontinuance to atomoxetine for any reason was fairly high, ranging from $13.7 \%{ }^{34}$ to $40.5 \% .^{35}$ One RCT reported that no patients discontinued atomoxetine prematurely, ${ }^{25}$ whereas a retrospective review of medical records of 27 patients reported that 17 (63\%) discontinued atomoxetine. ${ }^{36}$ In general, the rate of discontinuation of atomoxetine due to adverse effects was low. In the other studies where reason for discontinuation was given, discontinuation due to adverse effects ranged from $2.3 \%{ }^{37}$ to $6.7 \% .{ }^{38}$ In contrast, discontinuation for perceived lack of efficacy ranged from $8.4 \%{ }^{39}$ to $26 \% .{ }^{36}$ Patient choice, other than due to lack of efficacy or adverse effects, accounted for $56 \%$ of discontinuations in one study. ${ }^{29}$ Patients in the 15-21-year-old age group were most likely to discontinue treatment, with only $27 \%$ still being treated after 3 years and 11 months, whereas the overall rate of continuation for this period was $42 \%{ }^{30}$ This finding is consistent with a general unwillingness to continue chronic medications as an individual transitions from childhood to young adult..$^{30,40}$

One RCT in which patients were randomized to discontinue atomoxetine found that symptoms remained less severe than they were at study entry, and response was maintained after termination of atomoxetine. ${ }^{41}$

\section{Additional considerations}

Utilization patterns for medications used to treat ADHD (methylphenidate, atomoxetine, and modafinil) were examined from a "patient's perspective". ${ }^{42}$ The percentage of users who dropped out after only one prescription varied from $6 \%$ to $14 \%$, with a higher dropout in those age categories where treatment was off-label. ${ }^{42}$

An examination of treatment patterns of children and adolescents with ADHD in Germany found that few patients switched to atomoxetine $(1.5 \%$ of initial immediate-release methylphenidate users and $2.7 \%$ of modified-release methylphenidate users), whereas switches to methylphenidate occurred in $26.8 \%$ of atomoxetine initiators. ${ }^{43}$

It was observed that medication costs were higher for long-acting medications compared to short-acting ones and were highest for the nonstimulants. ${ }^{6}$ However, treatment adherence (dichotomous: $80 \%$ cutoff) was also lower for the short-acting vs long-acting medications $(9.8 \%$ vs $21.1 \%-25.8 \%$, respectively). ${ }^{6}$ It was suggested that the increased benefit in terms of better treatment adherence may outweigh the increased cost of long-acting preparations. ${ }^{6}$

The efficacy of different dosing regimens of atomoxetine was compared in adults with ADHD. ${ }^{44}$ On-label treatment (40 mg once daily for 3 days, then $80 \mathrm{mg}$ daily) was associated with a greater discontinuation due to an adverse event that was slow titration (40 mg once daily for 7 days, then $80 \mathrm{mg}$ daily), although the rate of patients experiencing adverse events was comparable. ${ }^{44}$

In a study of long-term outcomes via a questionnaire survey, it was found that $50 \%$ of patients taking atomoxetine $(n=13)$ reported not having missed a single dose during the previous week. ${ }^{24}$ Further, comorbidity at baseline predicted poorer outcome than did no comorbid illness. ${ }^{24}$

We identified one publication that reported on the differences in remission and treatment adherence with stimulants and atomoxetine in long-term treatment. Wagner et $\mathrm{al}^{45}$ examined service patterns and treatment outcomes from an ADHD medication service that implemented a Children's Medication Algorithm Project approach. Of the 47.0\% of children who progressed to a second medication trial, $88.7 \%$ tried a stimulant from a second class. In total, $19.7 \%$ tried atomoxetine, which was typically used as a third-stage choice (ie, after two different stimulant exposures). Stage 4-6 medications were rarely used; rather, stimulants were retried after atomoxetine and/or medication combinations were tried. Symptomatic remission at the end of treatment was achieved by $70.4 \%$ and $82.4 \%$ of children, according to parents and teachers, respectively, for those with outcome data and who completed treatment with any medication.

\section{Discussion}

Overall, relatively little data about the factors influencing adherence to atomoxetine treatment in patients with ADHD in comparison to other chronic mental disorders are available in the literature. The findings from this review indicate that persistence and adherence to atomoxetine treatment were generally high. Factors found to influence adherence and nonadherence to atomoxetine treatment in ADHD in this review include age, sex, the definition of response used, length of treatment, initial dose of treatment, comorbidities, and reimbursement. Tolerability was cited as an important reason for treatment discontinuation.

Poor medication adherence at the pediatric level may stem from the parents' initial hesitancy to have their child with ADHD treated with medication. ${ }^{46}$ ADHD is often perceived as a social, emotional, or psychological problem and related to willpower; thus, many patients and/or their caregivers inherently believe that pharmacological treatment is not necessary. Once the child has tried the medication, clear symptom benefit with few adverse effects and a simplified dosing schedule encourage families to continue its use. In the case of treatment with atomoxetine, in which 
a benefit may not be perceived immediately, the experience during the initial treatment period may greatly influence a parent's/caregiver's decision to continue or stop treatment. Other factors that may influence adherence include complexity of medication regimen (eg, number of daily doses, number of concurrent medications); treatment that requires mastery of certain techniques (eg, injections, inhalers); duration of therapy; frequent changes in medication regimen; medications with social stigma attached to their use; actual or perceived unpleasant side effects; and treatment that interferes with lifestyle or requires significant behavioral changes. ${ }^{47}$

When making decisions about medication, adolescents and adults with ADHD balance the positives and negatives, a behavior described by the health beliefs model. ${ }^{48}$ Participants reported the positives of medication in improving the core symptoms of ADHD, helping with school/college/work, and improving social relationships, along with the negatives of medication, which included physical side effects, effects on sense of self, loss of personality, stigma associated with medication use, and inconvenience of taking medication, especially when short-acting stimulants were used at school or at work.

\section{Medication adherence and discontinuation}

Among studies of adolescents, patients frequently expressed a desire for more autonomy and control over their conditions, prompting them to make decisions about medication treatment (reviewed in $\mathrm{McCarthy}^{40}$ ). When patients stopped taking medication, typically during adolescence, the decision was one that they often made themselves. Reasons included not wanting to take medication indefinitely, not perceiving a need for medication, believing that the medication does not work, and feeling that other negatives associated with medication use outweighed the positives. Stopping treatment may take the form of unplanned "drug holidays" or complete treatment cessation. Moreover, parents usually assume that their children are compliant.

Medication adherence is an area of considerable concern across varied chronic medical conditions (eg, asthma, diabetes, cardiovascular disorders). ${ }^{47}$ Depending on the chronic condition in question, medication adherence rates among pediatric populations can be as low as $11 \%$. $^{49}$ Regarding chronic illnesses in particular, parents often discontinue medications upon perceived resolution of symptoms, lack of effectiveness, or experience of adverse effects. ${ }^{50}$ Clinicians need to consider that ADHD often is perceived as a "noncritical" illness with no physical pain or discomfort associated, thus perception of a treatment need may be low.

Although treatment compliance and adherence are important issues in the management of all chronic medical and psychiatric conditions, ADHD shares many of the impediments to adequate compliance that are common to any lifelong condition. However, it also includes features and therapeutic responses that seem to be unique to individuals with ADHD (eg, a recent analysis showed that current methods of improving medication adherence for chronic health problems are mostly complex and not very effective, so the full benefits of treatment cannot be realized ${ }^{51}$ ). In addition, research in this field needs advances, including improved design of feasible long-term interventions, objective adherence measures, and sufficient study power to detect improvements in patient-important clinical outcomes. To address this important clinical challenge, the effectiveness of treatment adherence programs and related interventions, the role of guidelines, treatment modalities (such as formulation), and treatment strategies (such as dosage regimen simplification) must be scrutinized.

Although patient engagement in their treatment was not addressed in the present review, or in most of the articles included in this review, it appears that perhaps a greater degree of engagement may enhance adherence. In one survey, most general practitioners were unaware of the reason that many children and adolescents stopped taking atomoxetine as they progressed to adulthood. ${ }^{29}$ This age range is associated with poor adherence and may be attributed to a desire of the individual to take control of their condition and to not feel the need to continue medication..$^{29,30,40}$ It is likely that a deeper level of engagement, where the patient is seen more as a partner in planning their health care program, may lead to better treatment adherence overall.

In 2009, Dopheide detailed how the implementation of initiatives promoting medication adherence, such as patient/ parent education, provider follow-up, and adverse effect management, are critical to ensure treatment success. ${ }^{52}$ Although available evidence is limited and some findings may be difficult to interpret, the positive role of psychoeducation and other educational interventions in children and adolescents with ADHD regarding several outcome measures and treatment adherence is supported by most of the literature. ${ }^{53}$

\section{Factors affecting treatment adherence/ nonadherence}

It can often be difficult for health care professionals to understand the reasons for nonadherence among patients because 
the causes of nonadherence are often multidimensional. Treatment adherence is influenced by many factors: the health care team and system-related factors, condition-related factors, characteristics of therapies, and patient-related factors. ${ }^{11}$ These factors alone or in combination can lead a patient to become nonadherent. ${ }^{40}$ Because poor treatment adherence and discontinuation of therapy can result in symptom deterioration, providers should identify patients who do not adhere to medication schedules and their reason for nonadherence (eg, forgetfulness, side effects, parental support, parent, or child opposition) and provide strategies to overcome any barriers.

Nonadherence can also be categorized as unintentional (caused by poor memory and dexterity, or cost of medicines and lack of supervision) and intentional (caused by patients' own beliefs and decision-making abilities). In chronic disorders, a patient's belief about his or her treatment can be a significant predictor of adherence to that treatment. ${ }^{54}$ The decision to take a medication is complex, and there may be instances in which unintentional and intentional nonadherence interact.

Long-acting medications are associated with better treatment adherence and persistence compared with short-acting medications (both stimulants and nonstimulants). Further, higher doses of medication increase the likelihood of poor treatment adherence due to higher rates of side effects. ${ }^{55}$ Patients with intellectual difficulties are more likely to exhibit poorer treatment adherence. ${ }^{56}$ The presence of comorbidities and associated medications ${ }^{56,57}$ increases the treatment adherence. In addition, children who live in foster care $^{57}$ or with separated parents ${ }^{56}$ demonstrate increased treatment adherence. Factors associated with decreased treatment adherence and persistence include a family history of ADHD (especially paternal) and higher level of parental education. $^{55}$

Nonadherence to treatment regimens has been shown to be associated with increased hospital visits, unnecessary hospitalizations, increased symptoms of the disease, morbidity, and mortality. ${ }^{58,59}$ Adherence to treatment regimens has been shown to be related to improved psychological functioning and overall quality of health in youth and improvements in quality of life. ${ }^{60-63}$

\section{Remission with long-term treatment and maintenance of response}

Until recently, little information was available on relapse rates following treatment discontinuation. Atomoxetine has demonstrated maintenance of response in pediatric patients. $^{41,64}$ In one RCT where children and adolescents responded during an initial 12-week, open-label period of treatment with atomoxetine, response was maintained in patients randomized to continue on atomoxetine for an additional 9 months. ${ }^{64}$ Maintenance of response with atomoxetine treatment was analyzed in adults with ADHD during a 25-week, double-blind, placebo-controlled, randomized withdrawal period. ${ }^{65}$ Only adults who previously responded to atomoxetine during a 12-week, open-label treatment period and maintained that response during a 12-week, double-blind maintenance period were included in the study. Relapse was defined as a return to $\geq 80 \%$ of baseline Conners' Adult ADHD Rating Scale: InvestigatorRated: Screening Version total score after visit 11 (week 24) and two consecutive visits with a CGI-S score of $\geq 4$ points. More atomoxetine- than placebo-treated patients maintained a satisfactory response postrandomization (64.3\% vs 50.0\%; $P<0.001)$. Further, time-to-relapse was significantly longer for atomoxetine than placebo $(P=0.004)$. In addition, relapse rates after discontinuation of treatment with atomoxetine seem to be lower compared to those seen after discontinuation of stimulants, and the differences in relapse rates may be due to differences in the mechanism of action. ${ }^{66}$ However, this difference is also probably due to responders on atomoxetine (after long-term maintenance) being able to maintain response after discontinuation much longer, and this may result in increased treatment adherence.

\section{Sex differences and outcomes}

With the exception of two articles, the studies included in this review reported that a majority of subjects were male, ranging from a low of $56 \%{ }^{24}$ to a high of $90 \% .{ }^{41}$ Both studies reporting a greater proportion of female subjects, $62 \%{ }^{35}$ and $52 \%,{ }^{44}$ were performed with adult patients. This is consistent with reports that, over time, more females are diagnosed with ADHD, reducing the prevalence ratios. ${ }^{27}$ For example, Zetterqvist et $\mathrm{al}^{30}$ reported that the male-to-female prevalence ratio in children was 3.86 and dropped to 1.21 in adults. Most of the studies did not report on any interaction on outcome by sex. One study reported that males had a lower discontinuation rate than females ( $18 \%$ vs $22 \%$, respectively), ${ }^{43}$ whereas others indicated that females were more likely to show better adherence ${ }^{6,27}$ and greater persistence. ${ }^{6}$ Another study reported that females were more likely to show atomoxetine remission than males, whereas males showed poorer adherence. ${ }^{33}$ No significant influence of sex on outcome was reported in five studies. ${ }^{22,31,34,41,67}$ The interactions of sex on outcome may be influenced by the generally greater preponderance of 
male patients within the studies and require more balanced studies to be performed.

\section{Limitations of the study}

One of the potential limitations of this review is that adherence is measured by many different parameters, making comparisons across studies difficult. ${ }^{6}$ In the present investigation, adherence was determined by post hoc examination of medical records, questionnaires, direct questioning, or review of returned medications in an RCT. Consequently, the heterogeneous methods, trial design, and outcome measures that were considered likely limited the strength of the evidence included in this review. In spite of a comprehensive literature search and the inclusion of publications from different databases, it is still possible that we may have inadvertently excluded relevant publications. The patient numbers in some of the included articles were low (ie, <100), and of all the articles included, only five were of RCTs. Moreover, in cohort studies (including both prospective and retrospective designs, cross-sectional studies, and case-control studies), and in controlled trials, adherence and persistence are limited to compliance and discontinuation to treatment patients are taking in a controlled setting, thus the inclusion of real-world observational trials in this review may provide a better understanding of treatment adherence in a naturalistic setting.

In summary, although we are limited in our ability to draw robust conclusions from the available data, we recommend further research examining medication adherence, compliance, and discontinuation in atomoxetine-treated patients with ADHD. It is important to gain a clearer understanding of the factors that impact the treatment and management of ADHD and to address the unmet needs in clinical practice to make well-informed treatment decisions for this patient population and in order to better predict treatment adherence and prognosis. A more thorough understanding of treatment adherence can help clinicians individualize ADHD treatments and assess various factors upon initiation of treatment to improve education of patients and caregivers regarding treatment goals, course prediction, and proper dosing. In addition, we may further investigate the subsequent consequences of nonadherence/adherence after atomoxetine treatment on clinical outcomes, such as quality of life, longterm outcomes, functioning, and impact on comorbidity.

\section{Conclusion}

The findings from this review indicate that persistence and adherence to atomoxetine treatment were generally high. Factors found to influence treatment adherence and nonadherence to atomoxetine treatment in ADHD in this review include age, sex, the definition of response used, length of treatment, initial dose of treatment, comorbidities, and reimbursement. Tolerability was cited as an important reason for treatment discontinuation. A more thorough understanding of treatment adherence can help clinicians to individualize ADHD treatments and assess various factors upon initiation of treatment to improve education of patients and caregivers regarding treatment goals, course prediction, and proper dosing. More research is needed to understand those factors that can help identify patients at risk for poor treatment adherence and identify interventions that could improve treatment adherence early in the stage of this illness to secure a better long-term prognosis.

\section{Acknowledgments}

Funding for this study was provided by Eli Lilly and Company. The authors would like to thank Shannon Gardell, $\mathrm{PhD}$, and Michael Ossipov, PhD (inVentiv Health Clinical, LLC) for assistance with preparation of the manuscript and Angela Lorio, ELS and Jeanne Claypoole (inVentiv Health Clinical, LLC) for editorial assistance.

\section{Disclosure}

Drs Treuer, Mendéz, and Wu and Mr Montgomery are fulltime employees of Eli Lilly and Company, LLC, and minor stockholders of Eli Lilly and Company. The authors report no other conflicts of interest in this work.

\section{References}

1. Langberg JM, Becker SP. Does long-term medication use improve the academic outcomes of youth with attention-deficit/hyperactivity disorder? Clin Child Fam Psychol Rev. 2012;15:215-233.

2. Charach A, Fernandez R. Enhancing ADHD medication adherence: challenges and opportunities. Curr Psychiatry Rep. 2013;15:371.

3. Chacko A, Newcorn JH, Feirsen N, Uderman JZ. Improving medication adherence in chronic pediatric health conditions: a focus on ADHD in youth. Curr Pharm Des. 2010;16:2416-2423.

4. Charach A, Dashti B, Carson P, et al. Attention Deficit Hyperactivity Disorder: Effectiveness of Treatment in At-risk Preschoolers; Long-term Effectiveness in all ages; and Variability in Prevalence, Diagnosis, and Treatment. Report No: 12-EHC003-EF. Rockville, MD: Agency for Healthcare Research and Quality (US); 2011.

5. Buckley P. Adherence to Mental Health Treatment. New York, NY: Oxford University Press; 2009.

6. Barner JC, Khoza S, Oladapo A. ADHD medication use, adherence, persistence and cost among Texas Medicaid children. Curr Med Res Opin. 2011;27(Suppl 2):13-22.

7. Hong J, Novick D, Treuer T, et al. Predictors and consequences of adherence to the treatment of pediatric patients with attention-deficit/ hyperactivity disorder in Central Europe and East Asia. Patient Prefer Adherence. 2013;7:987-995.

8. Ahmed R, Aslani P. Attention-deficit/hyperactivity disorder: an update on medication adherence and persistence in children, adolescents and adults. Expert Rev Pharmacoecon Outcomes Res. 2013;13:791-815. 
9. Wietecha LA, Wang S, Saylor KE, Day KA, Wu SH, Kelsey D. Differential response profiles in children and adolescents with attentiondeficit/hyperactivity disorder: treatment with atomoxetine. Clin Pediatr (Phila). 2015;54:164-173.

10. Barkley RA. Global issues related to the impact of untreated attentiondeficit/hyperactivity disorder from childhood to young adulthood. Postgrad Med. 2008;120:48-59.

11. Sabate E. Adherence to Long-term Therapies: Policy for Action. Geneva, Switzerland: World Health Organization; 2001.

12. Osterberg L, Blaschke T. Adherence to medication. N Engl J Med. 2005; 353:487-497.

13. Cramer JA, Roy A, Burrell A, et al. Medication compliance and persistence: terminology and definitions. Value Health. 2008;11:44-47.

14. Thompson SJ, Bender K, Lantry J, Flynn PM. Treatment engagement: building therapeutic alliance in home-based treatment with adolescents and their families. Contemp Fam Ther. 2007;29:39-55.

15. Gruman J, Rovner MH, French ME, et al. From patient education to patient engagement: implications for the field of patient education. Patient Educ Couns. 2010;78:350-356.

16. Health Affairs [webpage on the Internet]. Health Policy Brief: Patient Engagement. [cited February 14, 2013]. Available from: http://www. healthaffairs.org/healthpolicybriefs/brief.php?brief_id=86. Accessed March 17, 2016.

17. Vaughan B, Fegert J, Kratochvil CJ. Update on atomoxetine in the treatment of attention-deficit/hyperactivity disorder. Expert Opin Pharmacother. 2009;10:669-676.

18. Camporeale A, Upadhyaya H, Ramos-Quiroga JA, et al. Safety and tolerability of atomoxetine hydrochloride in a long-term, placebo-controlled randomized withdrawal study in European and non-European adults with attention-deficit/hyperactivity disorder. Eur J Psychiatr. 2013;27: 206-224.

19. Camporeale A, Porsdal V, De Bruyckere K, et al. Safety and tolerability of atomoxetine in treatment of attention deficit hyperactivity disorder in adult patients: an integrated analysis of 15 clinical trials. J Psychopharmacol. 2015;29:3-14.

20. Clemow DB, Bushe CJ. Atomoxetine in patients with ADHD: a clinical and pharmacological review of the onset, trajectory, duration of response and implications for patients. J Psychopharmacol. 2015;29: 1221-1230

21. Moher D, Liberati A, Tetzlaff J, Altman DG. Preferred reporting items for systematic reviews and meta-analyses: the PRISMA Statement. Open Med. 2009;3:e123-e130.

22. Wehmeier PM, Dittmann RW, Banaschewski T. Treatment compliance or medication adherence in children and adolescents on ADHD medication in clinical practice: results from the COMPLY observational study. Atten Defic Hyperact Disord. 2015;7:165-174.

23. Savill N, Pelton J, Lenox-Smith A, Bushe CJ. A 12-week nursing support programme for carers of children and adolescents in the UK with attention deficit hyperactivity disorder prescribed atomoxetine. Ther Adv Psychopharmacol. 2013;3:65-71.

24. Lensing MB, Zeiner P, Sandvik L, Opjordsmoen S. Four-year outcome in psychopharmacologically treated adults with attention-deficit/ hyperactivity disorder: a questionnaire survey. J Clin Psychiatry. 2013; 74:e87-e93

25. Svanborg P, Thernlund G, Gustafsson PA, Hägglöf B, Poole L, Kadesjö B. Efficacy and safety of atomoxetine as add-on to psychoeducation in the treatment of attention deficit/hyperactivity disorder: a randomized, double-blind, placebo-controlled study in stimulant-naive Swedish children and adolescents. Eur Child Adolesc Psychiatry. 2009; 18:240-249.

26. Setyawan J, Guérin A, Hodgkins P, et al. Treatment persistence in attention deficit/hyperactivity disorder: a retrospective analysis of patients initiated on lisdexamfetamine vs other medications. J Med Econ. 2013; 16:1275-1289.

27. Hodgkins P, Sasané R, Meijer WM. Pharmacologic treatment of attention-deficit/hyperactivity disorder in children: incidence, prevalence, and treatment patterns in the Netherlands. Clin Ther. 2011;33: 188-203.
28. Lachaine J, Beauchemin C, Sasane R, Hodgkins PS. Treatment patterns, adherence, and persistence in ADHD: a Canadian perspective. Postgrad Med. 2012;124:139-148.

29. McCarthy S, Wilton L, Murray M, Hodgkins P, Asherson P, Wong IC. Management of adult attention deficit hyperactivity disorder in UK primary care: a survey of general practitioners. Health Qual Life Outcomes. 2013;11:22

30. Zetterqvist J, Asherson P, Halldner L, Långström N, Larsson H. Stimulant and non-stimulant attention deficit/hyperactivity disorder drug use: total population study of trends and discontinuation patterns 2006-2009. Acta Psychiatr Scand. 2013;128:70-77.

31. Bahmanyar S, Sundström A, Kaijser M, von Knorring AL, Kieler H. Pharmacological treatment and demographic characteristics of pediatric patients with attention deficit hyperactivity disorder, Sweden. Eur Neuropsychopharmacol. 2013;23:1732-1738.

32. Christensen L, Sasané R, Hodgkins P, Harley C, Tetali S. Pharmacological treatment patterns among patients with attention-deficit/ hyperactivity disorder: retrospective claims-based analysis of a managed care population. Curr Med Res Opin. 2010;26:977-989.

33. Treuer T, Feng Q, Desaiah D, et al. Predictors of pharmacological treatment outcomes with atomoxetine or methylphenidate in patients with attention-deficit/hyperactivity disorder from China, Egypt, Lebanon, Russian Federation, Taiwan, and United Arab Emirates. Int J Clin Pract. 2014;68:1152-1160.

34. Pottegård A, Bjerregaard BK, Kortegaard LS, Zoëga H. Early discontinuation of attention-deficit/hyperactivity disorder drug treatment: a Danish nationwide drug utilization study. Basic Clin Pharmacol Toxicol. 2015;116:349-353.

35. Lee SI, Song DH, Shin DW, et al. Efficacy and safety of atomoxetine hydrochloride in Korean adults with attention-deficit hyperactivity disorder. Asia Pac Psychiatry. 2014;6:386-396.

36. Torres A, Whitney J, Rao S, Tilley C, Lobel R, Gonzalez-Heydrich J. Tolerability of atomoxetine for treatment of pediatric attention-deficit/ hyperactivity disorder in the context of epilepsy. Epilepsy Behav. 2011; 20:95-102.

37. Takahashi M, Takita Y, Goto T, et al. An open-label, dose-titration tolerability study of atomoxetine hydrochloride in Japanese adults with attentiondeficit/hyperactivity disorder. Psychiatry Clin Neurosci. 2011;65:55-63.

38. Takahashi M, Goto T, Takita Y, Chung SK, Wang Y, Gau SS. Openlabel, dose-titration tolerability study of atomoxetine hydrochloride in Korean, Chinese, and Taiwanese adults with attention-deficit/ hyperactivity disorder. Asia Pac Psychiatry. 2014;6:62-70.

39. Durell TM, Pumariega AJ, Rothe EM, Tamayo JM, Baron D, Williams D. Effects of open-label atomoxetine on African-American and Caucasian pediatric outpatients with attention-deficit/hyperactivity disorder. Ann Clin Psychiatry. 2009;21:26-37.

40. McCarthy S. Pharmacological interventions for ADHD: how do adolescent and adult patient beliefs and attitudes impact treatment adherence? Patient Prefer Adherence. 2014;8:1317-1327.

41. Buitelaar JK, Michelson D, Danckaerts M, et al. A randomized, doubleblind study of continuation treatment for attention-deficit/hyperactivity disorder after 1 year. Biol Psychiatry. 2007;61:694-699.

42. Pottegård A, Bjerregaard BK, Glintborg D, Kortegaard LS, Hallas J, Moreno SI. The use of medication against attention deficit/hyperactivity disorder in Denmark: a drug use study from a patient perspective. Eur J Clin Pharmacol. 2013;69:589-598.

43. Garbe E, Mikolajczyk RT, Banaschewski T, et al. Drug treatment patterns of attention-deficit/hyperactivity disorder in children and adolescents in Germany: results from a large population-based cohort study. J Child Adolesc Psychopharmacol. 2012;22:452-458.

44. Young JL, Sarkis E, Qiao M, Wietecha L. Once-daily treatment with atomoxetine in adults with attention-deficit/hyperactivity disorder: a 24-week, randomized, double-blind, placebo-controlled trial. Clin Neuropharmacol. 2011;34:51-60.

45. Wagner DJ, Vallerand IA, McLennan JD. Treatment receipt and outcomes from a clinic employing the attention-deficit/hyperactivity disorder treatment guideline of the children's medication algorithm project. J Child Adolesc Psychopharmacol. 2014;24:472-480. 
46. Charach A, Skyba A, Cook L, Antle BJ. Using stimulant medication for children with ADHD: what do parents say? A brief report. J Can Acad Child Adolesc Psychiatry. 2006;15:75-83.

47. World Health Organization. Adherence to Long-Term Therapies: Evidence for Action. Geneva, Switzerland: World Health Organization; 2003. Available from: http://www.who.int/chp/knowledge/publications/ adherence_report/en/. Accessed February 3, 2016.

48. Charach A, Volpe T, Boydell KM, Gearing RE. A theoretical approach to medication adherence for children and youth with psychiatric disorders. Harv Rev Psychiatry. 2008;16:126-135.

49. Winnick S, Lucas DO, Hartman AL, Toll D. How do you improve compliance? Pediatrics. 2005;115:e718-e724.

50. Matsui D. Current issues in pediatric medication adherence. Paediatr Drugs. 2007;9:283-288.

51. Nieuwlaat R, Wilczynski N, Navarro T, et al. Interventions for enhancing medication adherence. Cochrane Database Syst Rev. 2014;11: CD000011.

52. Dopheide JA. The role of pharmacotherapy and managed care pharmacy interventions in the treatment of ADHD. Am J Manag Care. 2009;15: S141-S150.

53. Montoya A, Colom F, Ferrin M. Is psychoeducation for parents and teachers of children and adolescents with ADHD efficacious? A systematic literature review. Eur Psychiatry. 2011;26:166-175.

54. Horne R, Weinman J. Patients' beliefs about prescribed medicines and their role in adherence to treatment in chronic physical illness. J Psychosom Res. 1999;47:555-567.

55. Gau SS, Shen HY, Chou MC, Tang CS, Chiu YN, Gau CS. Determinants of adherence to methylphenidate and the impact of poor adherence on maternal and family measures. J Child Adolesc Psychopharmacol. 2006;16:286-297.

56. Atzori P, Usala T, Carucci S, Danjou F, Zuddas A. Predictive factors for persistent use and compliance of immediate-release methylphenidate: a 36-month naturalistic study. J Child Adolesc Psychopharmacol. 2009;19:673-681.

57. Palli SR, Kamble PS, Chen H, Aparasu RR. Persistence of stimulants in children and adolescents with attention-deficit/hyperactivity disorder. J Child Adolesc Psychopharmacol. 2012;22:139-148.

58. Milgrom H, Bender B, Ackerson L, Bowry P, Smith B, Rand C. Noncompliance and treatment failure in children with asthma. J Allergy Clin Immunol. 1996;98:1051-1057.

59. Rapoff MA. Commentary: pushing the envelope: furthering research on improving adherence to chronic pediatric disease regimens. $J$ Pediatr Psychol. 2001;26:277-278.

60. Drotar D, Greenley RN, Demeter CA, et al. Adherence to pharmacological treatment for juvenile bipolar disorder. J Am Acad Child Adolesc Psychiatry. 2007;46:831-839.

61. Ekberg H, Kyllönen L, Madsen S, Grave G, Solbu D, Holdaas H. Clinicians underestimate gastrointestinal symptoms and overestimate quality of life in renal transplant recipients: a multinational survey of nephrologists. Transplantation. 2007;84:1052-1054.
62. Fredericks EM, Magee JC, Opipari-Arrigan L, Shieck V, Well A, Lopez MJ. Adherence and health-related quality of life in adolescent liver transplant recipients. Pediatr Transplant. 2008;12:289-299.

63. Hommel KA, Davis CM, Baldassano RN. Medication adherence and quality of life in pediatric inflammatory bowel disease. J Pediatr Psychol. 2008;33:867-874

64. Michelson D, Buitelaar JK, Danckaerts M, et al. Relapse prevention in pediatric patients with ADHD treated with atomoxetine: a randomized, double-blind, placebo-controlled study. J Am Acad Child Adolesc Psychiatry. 2004;43:896-904.

65. Upadhyaya H, Ramos-Quiroga JA, Adler LA, Williams D, Tanaka Y, Lane JR. Maintenance of response after open-label treatment with atomoxetine hydrochloride in international European and non-European adult outpatients with attention-deficit/hyperactivity disorder: a placebo controlled, randomised withdrawal study. Eur J Psychiat. 2013;27:187-205

66. Peksel A, Upadhyaya H, Adams DH. Maintenance of effect in attention-deficit/hyperactivity disorder (ADHD): what do placebocontrolled randomized withdrawal studies of atomoxetine and stimulants tell us [abstract]? Bull Clin Psychopharmacol. 2015; 25(Suppl 1):S8.

67. Greenhill LL, Newcorn JH, Gao H, Feldman PD. Effect of two different methods of initiating atomoxetine on the adverse event profile of atomoxetine. J Am Acad Child Adolesc Psychiatry. 2007;46:566-572.

68. Setyawan J, Hodgkins P, Guerin A, et al. Comparing treatment adherence of lisdexamfetamine and other medications for the treatment of attention deficit/hyperactivity disorder: a retrospective analysis. $J$ Med Econ. 2013;16:962-975.

69. Kratochvil CJ, Newcorn JH, Arnold LE, et al. Atomoxetine alone or combined with fluoxetine for treating ADHD with comorbid depressive or anxiety symptoms. J Am Acad Child Adolesc Psychiatry. 2005;44: 915-924.

70. Adler L, Wilens T, Zhang S, et al. Retrospective safety analysis of atomoxetine in adult ADHD patients with or without comorbid alcohol abuse and dependence. Am J Addict. 2009;18:393-401.

71. Adler LA, Liebowitz M, Kronenberger W, et al. Atomoxetine treatment in adults with attention-deficit/hyperactivity disorder and comorbid social anxiety disorder. Depress Anxiety. 2009;26:212-221.

72. Wernicke JF, Adler L, Spencer T, et al. Changes in symptoms and adverse events after discontinuation of atomoxetine in children and adults with attention deficit/hyperactivity disorder: a prospective, placebo-controlled assessment. J Clin Psychopharmacol. 2004;24:30-35.

73. Allen AJ, Kurlan RM, Gilbert DL, et al. Atomoxetine treatment in children and adolescents with ADHD and comorbid tic disorders. Neurology. 2005;65:1941-1949.
Neuropsychiatric Disease and Treatment

\section{Publish your work in this journal}

Neuropsychiatric Disease and Treatment is an international, peerreviewed journal of clinical therapeutics and pharmacology focusing on concise rapid reporting of clinical or pre-clinical studies on a range of neuropsychiatric and neurological disorders. This journa is indexed on PubMed Central, the 'PsycINFO' database and CAS,

\section{Dovepress}

and is the official journal of The International Neuropsychiatric Association (INA). The manuscript management system is completely online and includes a very quick and fair peer-review system, which is all easy to use. Visit http://www.dovepress.com/testimonials.php to read real quotes from published authors. 